Laser Chem., 1999, Vol. 19, pp. 357-362

Reprints available directly from the publisher Photocopying permitted by license only
(C) 1999 OPA (Overseas Publishers Association) N.V. Published by license under the Harwood Academic Publishers imprint, part of The Gordon and Breach Publishing Group.

\title{
PHOTOINDUCED INTRAMOLECULAR HYDROGEN TRANSFER REACTION OF ORTHO NITROBENZYL COMPOUNDS
}

\author{
HIROAKI TAKAHASHI*, YOSHIKI WATANABE, \\ MAKOTO SAKAI and MASANORI TACHIKAWA \\ Department of Chemistry, School of Science and Engineering, Waseda \\ University, Tokyo 169, Japan
}

(Received 7 April 1997)

\begin{abstract}
Time-resolved resonance Raman and absorption spectra have revealed that the photoinduced intramolecular hydrogen transfer reaction of ortho nitrobenzyl compounds is initiated by the abstraction of methylene hydrogen by the ortho nitro group to generate the ortho aci-nitro acid isomer. In polar solvents the ortho aci-nitro acid is dissociated into the aci-nitro anion and a proton, and the proton is captured by other hydrogen accepting sites, such as 2-pyridyl, 4-pyridyl and 4-nitro groups to generate the ortho $\mathrm{N}-\mathrm{H}$ quinoid, para $\mathrm{N}-\mathrm{H}$ quinoid and para aci-nitro acid isomers, respectively. For 2-nitroethylbenzene and 2- and 4-(2'-nitrobenzyl)pyridines the structure of the aci-nitro anion is very similar to that of their respective ortho aci-nitro acid, while for 2,4-dinitroethylbenzene the structure of the aci-nitro anion quite resembles that of the para aci-nitro acid.
\end{abstract}

Keywords: Ortho nitrobenzyl compounds; photoinduced hydrogen transfer; time-resolved Raman; time-resolved absorption

\section{INTRODUCTION}

Benzyl derivatives having a nitro group at the ortho position are known to undergo photoinduced reversible intramolecular transfer of methylene hydrogen of the benzyl group. However, the detailed mechanism of this hydrogen transfer reaction is not well understood. This investigation was carried out with the purpose of obtaining

\footnotetext{
* Corresponding author.
} 
detailed information on the hydrogen transfer mechanism of ortho nitrobenzyl compounds having multiple possible hydrogen accepting sites using time-resolved Raman spectroscopy and laser flash photolysis with the help of $a b$ initio molecular orbital calculations.

\section{EXPERIMENTAL}

2-Nitroethylbenzene was purchased from Tokyo Kasei Kogyo Co. Ltd. 2,4-dinitroethylbenzene was synthesized by nitration of 2-nitroethylbenzene. 2-(2'-Nitrobenzyl)pyridine and 4-(2'-nitrobenzyl) pyridine were synthesized by nitration of commercially available 2-benzylpyridine and 4-benzylpyridine (Kanto Chemical Co. Inc.) to generate $2-\left(2^{\prime}, 4^{\prime}\right.$-dinitrobenzyl)pyridine and $4-\left(2^{\prime}, 4^{\prime}\right.$-dinitrobenzyl) pyridine, respectively, followed by elimination of the 4-nitro group through the diazonium salt.

\section{RESULTS AND DISCUSSION}

\section{2-Nitroethylbenzene (NEB)}

The transient absorption spectrum of NEB in methanol measured at $100 \mathrm{~ns}$ after the pumping with $308 \mathrm{~nm}$ light exhibited a band at $395 \mathrm{~nm}$ which decreased in intensity with time, but was not affected by the presence of oxygen. This band is assignable to the ortho aci-nitro acid isomer generated by hydrogen transfer from the methylene group to the ortho nitro group. With addition of $\mathrm{NaOH}$ in methanol solutions (about $1 / 20$ of NEB in molar concentration) the $395 \mathrm{~nm}$ band exhibited a shifting to $410 \mathrm{~nm}$ with time. The band at $410 \mathrm{~nm}$ can be attributed to the aci-nitro anion produced by dissociation of the ortho aci-nitro acid. Since the peak shift on the dissociation is small, the absorption of a small amount of the aci-nitro anion may well be hidden under the strong $395 \mathrm{~nm}$ band, and therefore, the possibility of the generation of a small amount of the aci-nitro anion in the hydrogen transfer reaction of NEB in neutral methanol solutions may not wholly be excluded.

The transient resonance Raman spectrum of NEB measured with $423 \mathrm{~nm}$ light at $100 \mathrm{~ns}$ after the $308 \mathrm{~nm}$ pumping in methanol was 
compared with that in $\mathrm{CCl}_{4}$ (Fig. 1). We found that the weak band at $1282 \mathrm{~cm}^{-1}$ observed in methanol solutions was missing in the spectrum of $\mathrm{CCl}_{4}$ solutions. Since the dissociation of the aci-nitro acid is expected to occur only in polar solvents, and NEB in alkaline methanol solutions exhibited a strong Raman band at $1288 \mathrm{~cm}^{-1}$, the $1282 \mathrm{~cm}^{-1}$ band observed in methanol solutions indicates that a small amount of the aci-nitro anion is produced in neutral methanol solutions.

It was observed that the spectrum of the aci-nitro anion is very similar to that of the aci-nitro acid. This implies that the structures of

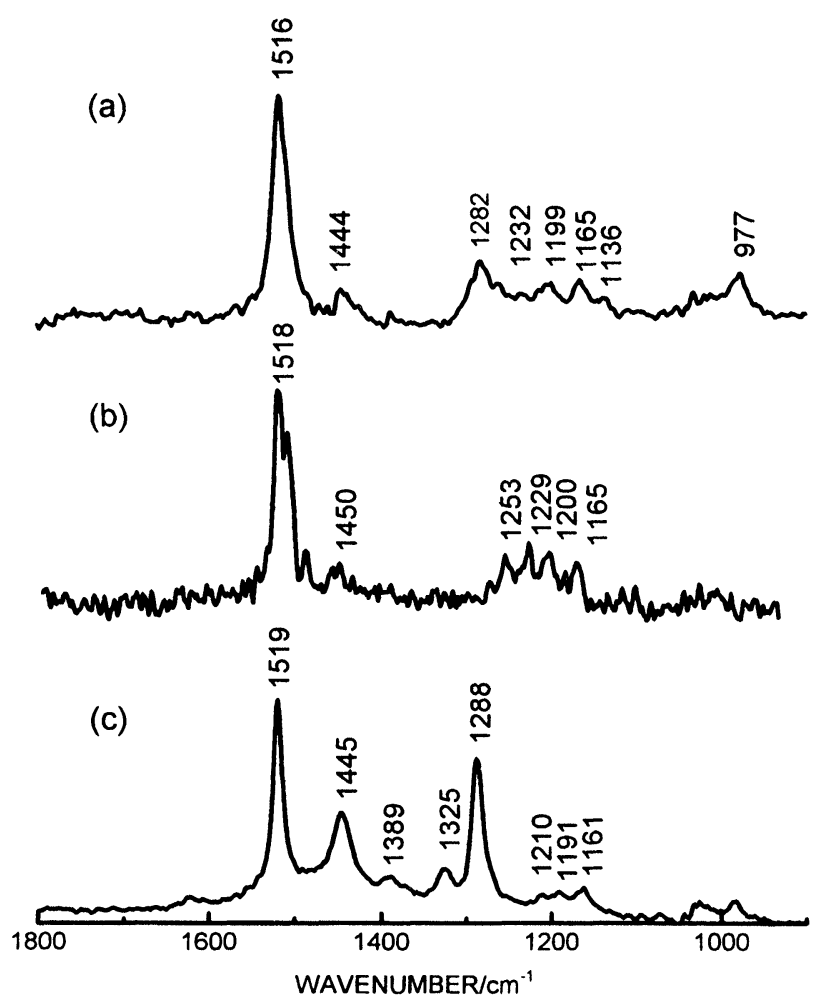

FIGURE 1 Transient resonance Raman spectra of NEB in different solvents (concentration, $1.0 \times 10^{-2} \mathrm{~mol} \mathrm{dm}^{-3}$ ) probed with $423 \mathrm{~nm}$ light: (a) methanol solution observed at $100 \mathrm{~ns}$; (b) $\mathrm{CCl}_{4}$ solution observed at $100 \mathrm{~ns}$; (c) basic methanol solution observed at $10 \mu \mathrm{s}$ (concentration of $\mathrm{NaOH}, 1.0 \times 10^{-3} \mathrm{~mol} \mathrm{dm}^{-3}$ ). Pump wavelength, $308 \mathrm{~nm}$. 
the both transients quite resemble each other. Also, the strong Raman band at about $1515 \mathrm{~cm}^{-1}$ observed in the both transients may be considered to be the characteristic band of the ortho quinoidal structure of the aci-nitro acid and its anion. Ab initio molecular orbital calculations of the optimized geometries and normal frequencies using the DFT(density functional theory)/B3LYP method nicely supported the above conclusions and showed that the $1515 \mathrm{~cm}^{-1}$ band is assigned to the symmetric stretch of the $\mathrm{C}=\mathrm{C}$ bonds in the ortho quinoidal ring.

\section{2-(2'-Nitrobenzyl)pyridine (2-NBP) and 4-( $2^{\prime}$-nitrobenzyl)pyridine (4-NBP)}

Since the hydrogen transfer reaction of 2-NBP is similar to that of 4-NBP, only 4-NBP is discussed here. 4-NBP in methanol exhibited an absorption band at $423 \mathrm{~nm}$ at $100 \mathrm{~ns}$ after the $308 \mathrm{~nm}$ pumping. At $2 \mu \mathrm{s}$ a shoulder appeared at ca. $390 \mathrm{~nm}$ and at $10 \mu$ s the $423 \mathrm{~nm}$ band with the $390 \mathrm{~nm}$ shoulder disappeared completely while new bands appeared at 379 and $544 \mathrm{~nm}$. These spectral changes were not observed in $\mathrm{CCl}_{4}$ solutions. The band at $423 \mathrm{~nm}$ can be assigned to the aci-nitro acid isomer. The shoulder at about $390 \mathrm{~nm}$ is attributed to the aci-nitro anion, because in basic methanol solutions a broad band assignable to the aci-nitro anion was observed at $392 \mathrm{~nm}$. The bands at 379 and $544 \mathrm{~nm}$ are assigned to the ortho $\mathrm{N}-\mathrm{H}$ quinoid isomer generated from the aci-nitro anion by accepting a proton at the nitrogen atom of the 4-pyridyl group.

The transient resonance Raman spectrum of 4-NBP in methanol measured with $423 \mathrm{~nm}$ light at $100 \mathrm{~ns}$ showed a strong band at $1512 \mathrm{~cm}^{-1}$, which is characteristic to the ortho aci-nitro acid structure, and a band at $1292 \mathrm{~cm}^{-1}$ with a shoulder at about $1280 \mathrm{~cm}^{-1}$. At $100 \mu$ s these bands disappeared and bands are observed at 1655,1592 and $1541 \mathrm{~cm}^{-1}$ which are attributable to the para $\mathrm{N}-\mathrm{H}$ quinoid isomer. The $1280 \mathrm{~cm}^{-1}$ shoulder may arise from the aci-nitro anion, because in basic methanol solutions the aci-nitro anion exhibited a strong bands at 1519 and $1277 \mathrm{~cm}^{-1}$. The transient resonance Raman spectrum measured with $390 \mathrm{~nm}$ light at $100 \mathrm{~ns}$ was almost the same as the spectrum of the aci-nitro anion. 


\section{2,4-Dinitroethylbenzene (DNEB)}

On irradiation with $308 \mathrm{~nm}$ light DNEB in methanol exhibited two absorption peaks at ca. 335 and $465 \mathrm{~nm}$ at $100 \mathrm{~ns}$ after the pumping. These bands decreased in intensity with time and at $10 \mu$ s a strong band appeared at $343 \mathrm{~nm}$. In basic methanol solutions two absorption peaks were observed at 363 and $393 \mathrm{~nm}$. The bands at ca. 335 and $465 \mathrm{~nm}$ are assignable to the ortho aci-nitro acid isomer. It was

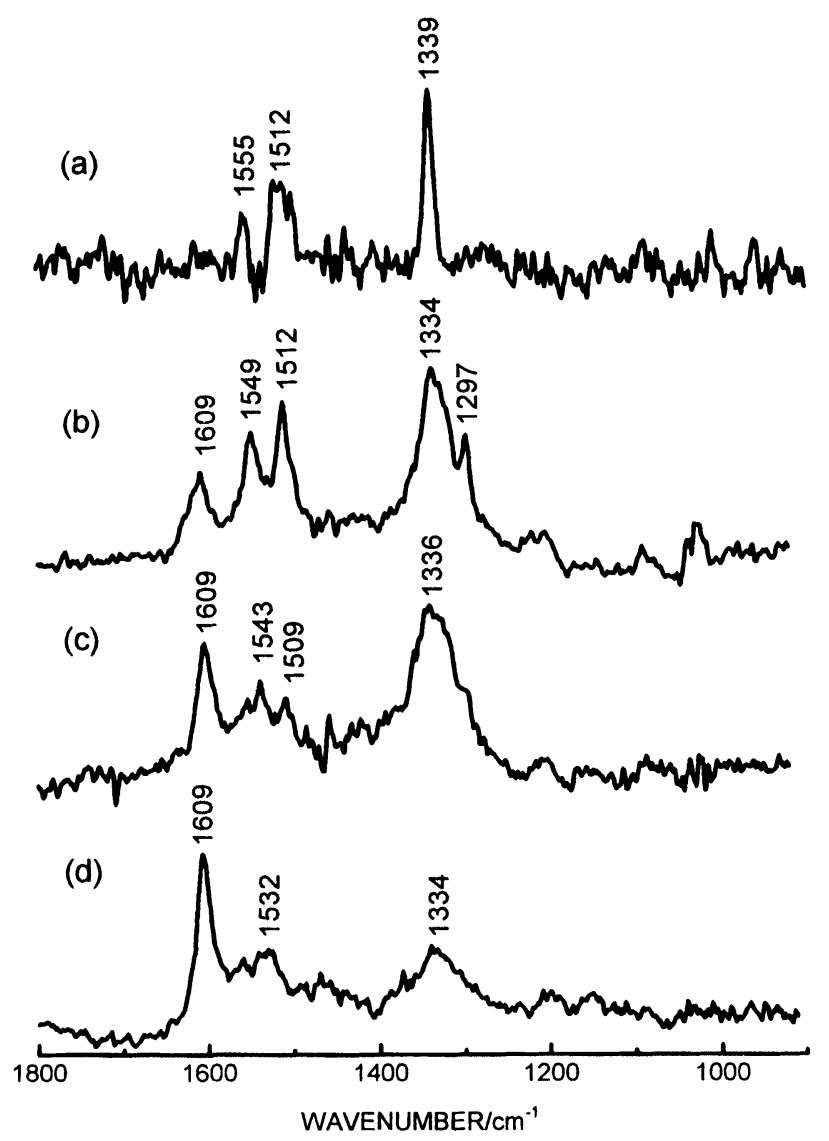

FIGURE 2 Transient resonance Raman spectra of DNEB in different solvents (concentration, $1.0 \times 10^{-2} \mathrm{~mol} \mathrm{dm}^{-3}$ ) probed with $456 \mathrm{~nm}$ light: (a) $\mathrm{CCl}_{4}$ solution observed at $100 \mathrm{~ns}$; (b) methanol solution observed at $100 \mathrm{~ns}$; (c) methanol solution observed at $100 \mu \mathrm{s}$; (d) basic methanol solution observed at $2 \mu \mathrm{s}$ (concentration of $\mathrm{NaOH}, 1.4 \times 10^{-4} \mathrm{~mol} \mathrm{dm}^{-3}$ ). Pump wavelength, $308 \mathrm{~nm}$. 
observed that in acidic methanol solutions the generation of the transient exhibiting the $343 \mathrm{~nm}$ band was markedly accelerated. The band at $343 \mathrm{~nm}$ can be attributed to the para aci-nitro acid isomer. The shortening of the rise time of the $343 \mathrm{~nm}$ band in acidic methanol solutions may be explained as due to the protonation of the 4-nitro group with the concomitant deprotonation of the ortho aci-nitro acid group to generate the para aci-nitro acid isomer. It is not clear from the absorption spectra whether or not the aci-nitro anion is produced in neutral methanol solutions as the precursor of the para aci-nitro acid.

The transient resonance Raman spectrum of DNEB probed with $456 \mathrm{~nm}$ light at $100 \mathrm{~ns}$ in methanol exhibited bands at 1609, 1549, 1512 and $1334 \mathrm{~cm}^{-1}$ (Fig. 2). The $1609 \mathrm{~cm}^{-1}$ band, however, was missing in the spectrum of $\mathrm{CCl}_{4}$ solutions. The band at 1549,1512 and $1334 \mathrm{~cm}^{-1}$ are attributable to the ortho aci-nitro acid isomer. The band at $1609 \mathrm{~cm}^{-1}$ is considered to arise from the aci-nitro anion, because basic methanol solutions exhibit a strong Raman band at $1609 \mathrm{~cm}^{-1}$ which is attributable to the aci-nitro anion. At $100 \mu$ s the band at 1609 became stronger and the bands at 1549 and $1512 \mathrm{~cm}^{-1}$ disappeared and new bands appeared at 1543 and $1509 \mathrm{~cm}^{-1}$. These bands are assigned to the para aci-nitro acid isomer. The spectral change with time indicates that the para aci-nitro acid was produced by the protonation of the aci-nitro anion which was generated by the dissociation of the ortho aci-nitro acid. On the basis of the similarity of the spectra it is concluded that the structure of the aci-nitro anion is very similar to that of the para aci-nitro acid. 